\title{
Two distinct microbial communities revealed in the sponge Cinachyrella
}

\section{Marie L. Cuvelier ${ }^{1 *}$, Emily Blake ${ }^{2}$, Rebecca Mulheron ${ }^{2}$, Peter J. McCarthy ${ }^{3}$, Patricia Blackwelder ${ }^{2,4}$, Rebecca L. Vega Thurber ${ }^{5}$ and Jose V. Lopez ${ }^{2}$}

${ }^{1}$ Biological Sciences Department, Florida International University, Miami, FL, USA

2 Oceanographic Center, Nova Southeastern University, Dania Beach, FL, USA

${ }^{3}$ Marine Biomedical and Biotechnology Research, Harbor Branch Oceanographic Institute, Florida Atlantic University, Fort Pierce, FL, USA

${ }^{4}$ Marine Geosciences, Rosenstiel School of Marine and Atmospheric Science, University of Miami, Miami, FL, USA

${ }^{5}$ Department of Microbiology, Oregon State University, Corvallis, OR, USA

Edited by:

Torsten Thomas, The University of New South Wales, Australia

Reviewed by:

Megan Jane Huggett, Edith Cowan

University, Australia

Heidi M. Luter, Charles Darwin

University, Australia

Robert W. Thacker, University of

Alabama at Birmingham, USA

*Correspondence:

Marie L. Cuvelier, Biological

Sciences Department, Florida

International University, $3000 \mathrm{NE}$

151st Street, Miami, FL, USA

e-mail: cuvelierm/@gmail.com
Marine sponges are vital components of benthic and coral reef ecosystems, providing shelter and nutrition for many organisms. In addition, sponges act as an essential carbon and nutrient link between the pelagic and benthic environment by filtering large quantities of seawater. Many sponge species harbor a diverse microbial community (including Archaea, Bacteria and Eukaryotes), which can constitute up to $50 \%$ of the sponge biomass. Sponges of the genus Cinachyrella are common in Caribbean and Floridian reefs and their archaeal and bacterial microbiomes were explored here using 16S rRNA gene tag pyrosequencing. Cinachyrella specimens and seawater samples were collected from the same South Florida reef at two different times of year. In total, 639 OTUs (12 archaeal and 627 bacterial) belonging to 2 archaeal and 21 bacterial phyla were detected in the sponges. Based on their microbiomes, the six sponge samples formed two distinct groups, namely sponge group 1 (SG1) with lower diversity (Shannon-Wiener index: $3.73 \pm 0.22$ ) and SG2 with higher diversity (Shannon-Wiener index: $5.95 \pm$ 0.25). Hosts' $28 \mathrm{~S}$ rRNA gene sequences further confirmed that the sponge specimens were composed of two taxa closely related to Cinachyrella kuekenthalli. Both sponge groups were dominated by Proteobacteria, but Alphaproteobacteria were significantly more abundant in SG1. SG2 harbored many bacterial phyla ( $>1 \%$ of sequences) present in low abundance or below detection limits $(<0.07 \%)$ in SG1 including: Acidobacteria, Chloroflexi, Gemmatimonadetes, Nitrospirae, PAUC34f, Poribacteria, and Verrucomicrobia. Furthermore, SG1 and SG2 only had 95 OTUs in common, representing 30.5 and $22.4 \%$ of SG1 and SG2's total OTUs, respectively. These results suggest that the sponge host may exert a pivotal influence on the nature and structure of the microbial community and may only be marginally affected by external environment parameters.

Keywords: marine sponge, symbionts, diversity, archaea, pyrosequencing, 16S rRNA, microbiome

\section{INTRODUCTION}

Sponges are one of the most primitive Metazoan life forms with fossils dating from at least 580 million years ago (Li et al., 1998; Ryan et al., 2013). Today, there are more than 8500 described extant sponge species, most of which are marine (van Soest et al., 2012). Marine sponges are ecologically important components of the benthic community due to their wide diversity and high biomass (Ilan et al., 2004; de Goeij et al., 2013). In addition, they play a key functional role linking benthic and pelagic ecosystems, as they efficiently remove particulate organic carbon from the seawater (Díaz and Rützler, 2001; Ilan et al., 2004; Webster et al., 2011). Indeed, these sessile invertebrates are able to filter

Abbreviations: $\mathrm{AOA}$, ammonia-oxidizing archaea; $\mathrm{AOB}$, ammonia-oxidizing bacteria; LMA, low microbial abundance; HMA, high microbial abundance; SG1, sponge group 1; SG2, sponge group 2 . considerable amounts of seawater; a $1 \mathrm{~kg}$ sponge can filter up to $24000 \mathrm{~L}$ of water per day (Vogel, 1977). Because they are efficient filter feeders, many sponges can live in nutrient-poor habitats such as tropical reefs. However, because of their feeding mode, they are also directly affected by water quality and are vulnerable to marginal environmental conditions (Webster and Blackall, 2009).

Many sponge species consistently harbor dense and diverse microbial communities including bacteria, archaea and eukaryotes (Taylor et al., 2007b). Symbionts can contribute up to $50 \%$ of the sponge biomass (Wilkinson, 1978a,b,c; Hentschel et al., 2006). Sponge-associated microorganisms include members of two archaeal lineages and $>30$ different bacterial and candidate phyla (Taylor et al., 2007b; Webster et al., 2008; Zhu et al., 2008; Sipkema et al., 2009; Schmitt et al., 2012). Many of these taxa form monophyletic sponge-specific clusters 
even though they are found in geographically and phylogenetically distinct sponge hosts (Taylor et al., 2007b; Simister et al., 2012).

Although sequencing technology has revealed much about the structural diversity of sponge associated microbiomes, relatively little is known about the specific ecological relationships and interactions among these sponge symbionts and their host (Taylor et al., 2007a; Webster and Taylor, 2012). While sponges are believed to provide a favorable environment to their symbionts, the contribution of the symbionts to the host is less well understood. However, phylogenetic inference suggests that associated bacteria and archaea are capable of a range of metabolic processes that can benefit their hosts such as ammonium-oxidation (Steger et al., 2008), nitrite-oxidation (Hentschel et al., 2002), nitrogen fixation (Wilkinson and Fay, 1979), sulfate reduction (Hoffmann et al., 2005), and photosynthesis (Wilkinson and Fay, 1979; Bayer et al., 2008; Hoffmann et al., 2009; Mohamed et al., 2010; Schläppy et al., 2010). However, it is possible that sponges and some, or all, of their microbes coexist in a more commensal or even parasitic style relationship with their hosts as opposed to a truly mutualistic one.

Further, how sponges distinguish between symbionts, food and pathogens is still unclear (Webster and Blackall, 2009). Recent studies have compared sponge microbial communities from phylogenetically distant hosts in the same location and from closely related sponges at different locations (Hentschel et al., 2002; Webster et al., 2010; Schmitt et al., 2012; Jeong et al., 2013; Montalvo et al., 2014; Kennedy et al., 2014). Thus, studies have established a "core microbial community" that would be present in many host taxa under various space and time conditions (Schmitt et al., 2012).

Here, we compare the microbial communities of different specimens of the sponge genus Cinachyrella collected from the same South Florida location at two different times of year. Cinachyrella (class Demospongiae), is common in coastal waters of South Florida as well as the Caribbean, with three species (C. kuekenthali, C. alloclada, and C. apion) present in these locations (Cárdenas et al., 2009). While C. apion is usually small and lives mainly near the mangrove area in shallow waters, C. kuekenthali and C. alloclada typically occur on reefs (Rützler and Smith, 1992; Cárdenas et al., 2009). However, these species are extremely difficult to visually differentiate and require careful examination of the spicules for identification at the species level (Cárdenas et al., 2009, personal observation).

Much debate currently exists concerning the identification of these species, with morphological diagnostic characters conflicting with molecular phylogenies created from marker genes. For example, using the 28S rRNA gene, cox 1 gene and a combination of the two former genes and 18S rRNA, Szitenberg et al. (2013) showed that, Cinachyrella australiensis contains several cryptic sympatric populations. Within the present study, we explore the microbiome of Cinachyrella specimens collected from the same natural environment. The purpose of the study was to describe the baseline microbial community of Cinachyrella in order to develop this sponge as a future experimental model. Interestingly, we discovered that based on different microbial communities, our samples formed two distinct groups of sponges, independent of the time of collection, indicating that Cinachyrella can harbor very distinct symbionts.

\section{MATERIAL AND METHODS SPONGE AND SEAWATER COLLECTION}

Cinachyrella specimens were collected by SCUBA diving from the Inner Reef (as defined by Walker, 2012), Broward County, Florida, USA ( $26^{\circ} 03^{\prime} 01^{\prime \prime}, \mathrm{W} 80^{\circ} 06^{\prime} 18^{\prime \prime}$ ) at a depth of $6.1 \mathrm{~m}$, on Aug 2, 2011, on Oct 24, 2011, and Feb 15, 2012, under a Florida Fish and Wildlife Conservation Commission Fishing License and a Special Activity License (-12-1372-372a). Sponges were identified as the genus Cinachyrella (family Tetillidae, Sollas, 1886; van Soest et al., 2014) given their characteristic orange to yellow color, subglobular shape and hispid surface. Water temperatures reached 30.3 , 23.9, and $22.8^{\circ} \mathrm{C}$ in August, October and February, respectively. A total of 64 individuals were collected in total. Here, we present detailed results for six individuals consisting of three individuals on October and February (henceforth labeled as Sponge 1, 2, 3 (Sp1, Sp2, Sp3) Oct and Sponge 4, 5, 6 (Sp4, Sp5, Sp6) Feb. The other 58 individuals were subjected to various experimental conditions in aquaculture, and we provide a preliminary analysis of these samples (Supplementary Material). In-depth results of the different experiments for these samples are not shown. Individuals were cut at the base with a dive knife, placed in individual Nasco Whirl Pak bags filled with ambient seawater and brought to the surface. Samples were stored in the shade and maintained at ambient seawater temperature until transported back to the laboratory (within $2 \mathrm{~h}$ of collection). Surface seawater was also collected each time (one replicate in October and one replicate in February) from the dive site in $50 \mathrm{~L}$ carboys. These seawater samples were used to confirm that microbial communities associated with the sponge were specific to the sponges and not amplified from seawater DNA. Upon return to the laboratory, sponges were quartered with a sterile knife, frozen in liquid nitrogen, and placed at $-80^{\circ} \mathrm{C}$ for long-term storage. Seawater $(0.5 \mathrm{~L})$ was filtered onto a $0.22 \mu \mathrm{m}$ Supor filter (Pall Life Science, Ann Arbor, MI) by vacuum filtration $(<10 \mathrm{~mm} \mathrm{Hg})$, the filters were frozen in liquid nitrogen, and stored at $-80^{\circ} \mathrm{C}$.

\section{DNA EXTRACTION}

Approximately $1 / 4$ of a sponge was used for DNA extraction. In a sterile petri dish, the sample was defrosted and the ectoderm (darker outer layer) was immediately removed using a sterile scalpel. The endoderm was transferred to a new petri dish and $5 \mathrm{ml}$ of buffer $(10 \mathrm{mM}$ Tris $\mathrm{pH}=7.6,100 \mathrm{mM}$ EDTA, $20 \mathrm{mM}$ $\mathrm{NaCl}$ ) was added. The sponge endoderm was minced, mixed in buffer, and the cell suspension collected into $1.7 \mathrm{~mL}$ tubes. These sponge suspensions were centrifuged for $15 \mathrm{~min}$ at 16,000 $g$ at $4^{\circ} \mathrm{C}$. Supernatant was decanted and the pellets transferred and extracted using the MO BIO PowerSoil DNA isolation kit according to the manufacturer's instructions (MO BIO, Carlsbad, CA).

Seawater filters also were extracted with the MO BIO PowerSoil kit to avoid yield discrepancy between DNA extraction protocols. The filters were placed into bead tubes (provided by the kit) and cut into fine pieces using sterile dissection scissors. DNA was extracted according to the manufacturer's instructions 
using a 2 min bead-beating step (instead of 10 min vortexing step).

\section{SPONGE 28S rRNA GENE PCR AND ANALYSIS}

For molecular systematics, our methods followed those proscribed by the Porifera Tree of Life project (Thacker et al., 2013). Specifically, the $28 \mathrm{~S}$ rRNA gene was amplified using the 28F63mod (5' - ACC CGC TGA AYT TAA GCA TAT HAN TMA G- $\left.3^{\prime}\right)$ and 28R2077sq (5'- GAG CCA ATC CTT WTC CCG ARG TT- 3') (Thacker et al., 2013). PCR consisted of one reaction of $50 \mu \mathrm{L}$ with: $1 \mu \mathrm{M}$ each forward and reverse primer, $1 \mu \mathrm{L}$ of template DNA, $2.5 \mathrm{mM} \mathrm{MgCl}_{2}, 0.2 \mathrm{mM}$ dNTPs and 1.25 unit of Taq (High Fidelity Taq, TaKARa Otsu, Shiga, Japan). Thermal cycling was initiated with denaturation at $94^{\circ} \mathrm{C}$ for $3 \mathrm{~min}$, followed by 30 cycles of: $45 \mathrm{~s}$ at $94^{\circ} \mathrm{C}, 60 \mathrm{~s}$ at $55^{\circ} \mathrm{C}$, and $72^{\circ} \mathrm{C}$ for $6 \mathrm{~min}$ and a final extension step for $10 \mathrm{~min}$ at $72^{\circ} \mathrm{C}$. PCR products were visualized on a $1.5 \%$ agarose gel (containing Gel Red). PCR products were cloned and sequenced on an ABI 377 automated DNA sequencer at the University of Alabama, Birmingham using the primer: 28R1411 (5'-GTT GTT ACA CACTCC TTA GCG G-3'). Two samples (Sp5 Feb and Sp6 Feb) had low quality sequences and were removed from the study. The nearest relative for each sequence was determined using the NCBI BLASTn tool against the GenBank non redundant database.

\section{S rRNA GENE PCR AND ANALYSIS}

Approximately $291 \mathrm{bp}$ of the $16 \mathrm{~S}$ rRNA gene was amplified by PCR using the universal bacterial and archaeal primers (targeting the V4 region of the gene): 515F ( $5^{\prime}$ - GTGCCAGCMGCCG CGGTAA- $3^{\prime}$ ) and 806R (5' - GGACTACHVGGGTWTCTAAT- $3^{\prime}$ ) (Caporaso et al., 2011), which contained a unique barcode used to tag each PCR product. This primer set was chosen because it targets a broad range of bacterial and archaeal taxa with the exception of a few groups (Bates et al., 2011; Caporaso et al., 2011). PCR consisted of two reactions of $30 \mu \mathrm{L}$ with (for each reaction): $1 \mu \mathrm{M}$ each forward and reverse primer, $1 \mu \mathrm{L}$ of template DNA, $2.5 \mathrm{mM}$ $\mathrm{MgCl}_{2}, 0.2 \mathrm{mM}$ dNTPs and 1.25 unit of Taq (High Fidelity Taq, TaKARa Otsu, Shiga, Japan). Thermal cycling was initiated with denaturation at $94^{\circ} \mathrm{C}$ for $3 \mathrm{~min}$, followed by 30 cycles of: $45 \mathrm{~s}$ at $94^{\circ} \mathrm{C}, 60 \mathrm{~s}$ at 50 and $72^{\circ} \mathrm{C}$ for $90 \mathrm{~s}$ and a final extension step for $10 \mathrm{~min}$ at $72^{\circ} \mathrm{C}$. PCR products were visualized on a $1.5 \%$ agarose gel (containing Gel Red). Successful reactions (i.e., with a clear band, two reactions of $25 \mu \mathrm{L}$ ) were pooled and purified with the Agencourt AMPure kit (Beckman Coulter, Beverly, MA), using $1.8 \times$ vol. of AMPure bead slurry and eluted in $10 \mathrm{mM}$ Tris $\mathrm{pH}$ 7.5. Each sample was quantified using PicoGreen dsDNA reagent (Invitrogen, Carlsbad, CA). Purified products were sequenced on a 454 Life Science Genome Sequencer FLX (Roche) at Advanced Genetic Technologies Center at the University of Kentucky.

Sequences were analyzed using QIIME version 1.6 (Caporaso et al., 2010b). Only sequences with a mean quality score $>25$ and of length $>280 \mathrm{bp}$ were included in the analysis. Sequences were then assigned to each barcode and denoised using the denoise_wrapper option (Reeder and Knight, 2010) in QIIME. Operational Taxonomic Units (OTU) were picked using the UCLUST method (Edgar, 2010) and sequences with $\geq 97 \%$ identities were considered as one OTU. A representative sequence was chosen for each OTU and the taxonomic identity of each representative was assigned (in QIIME) using the RDP Classifier (Wang et al., 2007) against the Greengene 12_10 database (McDonald et al., 2012). Chimera sequences were removed using the ChimeraSlayer option (Haas et al., 2011). Sequences were aligned (using PyNAST with default paramaters set in QIIME, Caporaso et al., 2010a) and screened with Lane mask to remove gaps and hypervariable regions (Lane, 1991). A representative phylogenetic tree was built using FastTree (Price et al., 2010) and used for further analysis in QIIME (alpha, beta diversity from weighted UniFrac, Lozupone and Knight, 2005 and principal coordinate analysis generated from the UniFrac distances). $T$-tests (Microsoft Excel) were used to compare the relative abundance of each microbial phylum present in the samples of SG1 and SG2. A P value less than 0.05 was considered statistically significant. A principal coordinate analysis generated from the weighted UniFrac distances and an analysis of similarity (ANOSIM, 999 permutations) were generated in QIIME for all the 64 sponge individuals.

\section{RESULTS \\ MOLECULAR PHYLOGENETICS CONFIRM SPONGES ARE CINACHYRELLA}

All the partial 28S rRNA gene sequences obtained were most similar to the single C. kuekanthali 28S rRNA sequence present in Genbank (KC869490.1). Two 28S rRNA gene sequences (Sp5 and Sp6) could not be included in this study because of poor quality. Sp1 Oct and Sp4 Feb displayed 97\% identity to C. kuekanthali and Sp2 Oct and Sp3 Oct had 99\% identity to the same sequence (C. kuekanthali). Results showed that Sp1 Oct and Sp4 Feb were most closely related to each other (99.3\% identity compared to $\sim 97 \%$ identity to the other two samples). Similarly, Sp2 Oct and Sp3 Oct were 100\% identical to each other respectively, but only $\sim 97 \%$ identical to the other two samples (Table 1). Based on the 28S rRNA gene sequences, the samples therefore form two groups, one group including: Sp1 Oct and Sp4 Feb and another group including: Sp2 Oct and Sp3 Oct. These are similar to the two groups observed after analysis of the microbiomes (see below).

\section{CINACHYRELLA SPECIMENS HARBOR A DIVERSITY OF UNIQUE BACTERIA AND ARCHAEA}

After quality control and chloroplast sequence removal, a total of 16,811 sequences were analyzed including 13,947 from

Table 1 | Percent identity between the 28S rRNA gene partial sequences of Cinachyrella samples (Sp1- 4: sponge 1- 4) collected in October 2011 (Oct) and February 2012 (Feb) from South Florida and C. kuekenthali (C. kuek.; GenBank: KC869490.1; Panama).

\begin{tabular}{lccccc}
\hline & Sp1 Oct & Sp2 Oct & Sp3 Oct & Sp4 Feb & C. kuek. \\
\hline Sp1 Oct & 100 & & & & \\
Sp2 Oct & 97.3 & 100 & & & \\
Sp3 Oct & 97.3 & 100 & 100 & & \\
Sp4 Feb & 99.3 & 96.9 & 96.9 & 100 & \\
C. kuek & 96.9 & 99.8 & 99.8 & 96.5 & 100
\end{tabular}


sponges (ranging from 1185 to 3616 sequences/animal) and 2864 from seawater (ranging from 1340 to 1524 sequences/sample) (Table 2). Results indicated that Cinachyrella specimens harbor a diverse community of symbionts, including members of all three Domains of life (Bacteria, Archaea and Eukaryotes). Here, the analysis of the eukaryotic community is not presented. In total, 951 OTUs (measured at 97\% identity) were identified among all samples (including seawater), of which 19 were archaeal and 932 were bacterial. A total of 639 OTUs (12 archaeal and 627 bacterial OTUs) were present in the sponge symbiont community, and OTU richness in the sponges was lower than the seawater except for one sample (Sp3 Oct, 341 OTUs). The seawater microbial community contained a total of 450 OTUs (10 archaeal and 440 bacterial OTUs), and OTU richness was similar in both samples (246 vs. 285 OTUs) across sampling times (Table 2).

\section{CINACHYRELLA CONTAIN DISTINCT AND CANALIZED MICROBIOMES COMPARED TO SEAWATER}

Rarefaction analysis demonstrated that for some samples (Seawater Oct, Seawater Feb, Sp2 Oct and Sp3 Oct), the diversity was high enough such that sequencing depth was likely not sufficient to evaluate the rarer members of the community and that further sequencing would be necessary to reveal the true diversity (Supplementary Figure 1). Yet the rarefaction analysis here confirmed that most sponge samples' microbiome was less diverse than seawater (Supplementary Figure 1). Chaol richness estimates for sponges varied from 124 to 529 phylotypes and 440 and 510 OTUs for the seawater $(t=-1.9,0.05<P<0.1)$. Similarly, the Shannon-Wiener indices for the Cinachyrella samples were lower on average (3.1-6.2), but not statistically different than for the seawater (6.2 and 6.3; Table $2 t=-1.9,0.05<P<0.1$ ).

Comparatively, 21 bacterial and 2 archaeal phyla and candidate phyla were detected in the sponges vs. 27 bacterial and 2

\begin{tabular}{|c|c|c|c|c|c|}
\hline Sample ID & $\begin{array}{c}\text { Total } \\
\text { \#reads }\end{array}$ & $\begin{array}{c}\text { Total } \\
\text { OTUs }{ }^{\#}\end{array}$ & Chao1* & $\begin{array}{c}\text { Observed } \\
\text { OTUs* }\end{array}$ & Shannon* \\
\hline \multicolumn{6}{|l|}{ SEAWATER } \\
\hline SW Oct & 1340 & $246(0)$ & 440 & 221 & 6.2 \\
\hline SW Feb & 1524 & $285(1)$ & 510 & 239 & 6.3 \\
\hline \multicolumn{6}{|c|}{ GROUP "SG1" } \\
\hline Sp1 Oct & 1185 & $90(2)$ & 176 & 86 & 3.7 \\
\hline Sp4 Feb & 2386 & $179(0)$ & 267 & 119 & 4.2 \\
\hline Sp5 Feb & 1755 & $105(1)$ & 191 & 79 & 3.3 \\
\hline Sp6 Feb & 3616 & $115(1)$ & 124 & 61 & 3.1 \\
\hline \multicolumn{6}{|c|}{ GROUP "SG2" } \\
\hline Sp2 Oct & 2254 & $220(1)$ & 289 & 156 & 5.7 \\
\hline Sp3 Oct & 2751 & $341(0)$ & 529 & 203 & 6.2 \\
\hline
\end{tabular}

archaeal phyla and candidate phyla in the seawater. Here, we use the term "candidate phylum" to define a phylum that can be identified from genetic sequences, but lacks cultured representatives (Hugenholtz et al., 1998). Most bacterial sequences were classified, but a small portion $(2.7 \pm 0.9 \%$ in sponges and $2.8 \pm$ $0.003 \%$ in seawater samples) could not be assigned to any known phylum.

\section{MICROBIAL COMMUNITY COMPOSITION DEFINES TWO CINACHYRELLA TAXA}

Both sequence taxonomy (Table 1) and PCoA analyses (Figure 1) suggest that the Cinachyrella specimens in this study form two distinct groups and may represent different taxa of sponge. We defined here these groups as Sponge Group 1 (SG1) and Sponge Group 2 (SG2; Figure 1). SG1 incorporates samples that spanned both seasons (Sp1 Oct, Sp4 Feb, Sp5 Feb, and Sp6 Feb) while SG2 is composed of just two samples from one season (Sp2 Oct and Sp3 Oct). In addition, the PCoA analysis for all 64 sponges samples (See Material and Methods) confirmed that Sp1-6 were split among two groups of sponges defined by their microbial communities (Supplementary Figure 2), even though 58 of these samples were placed in aquaculture under various conditions (results of experiments not shown). ANOSIM analysis (using all 64 sponge samples) confirmed that these were statistically different $(R=0.9926, P=0.001)$.

The marked differences in these two groups are demonstrated by comparisons of the diversity of microbial taxa in each. SG2

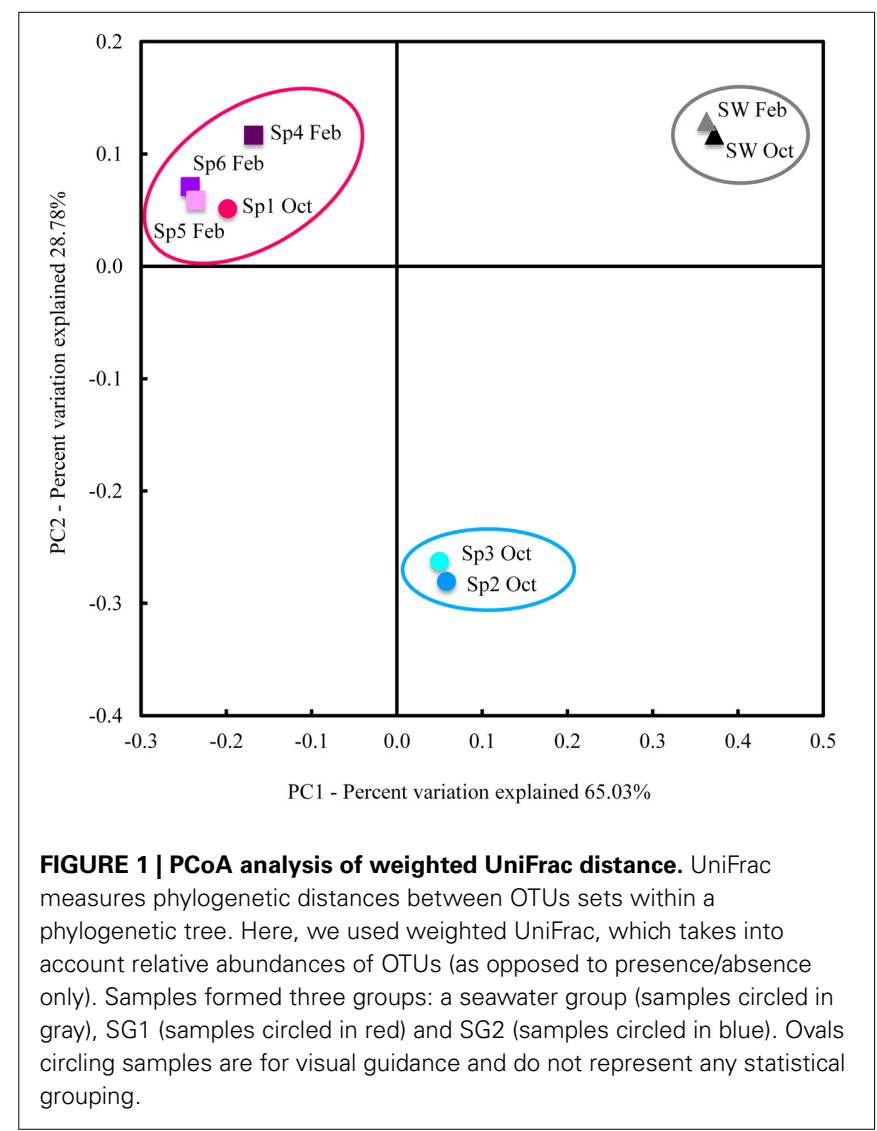




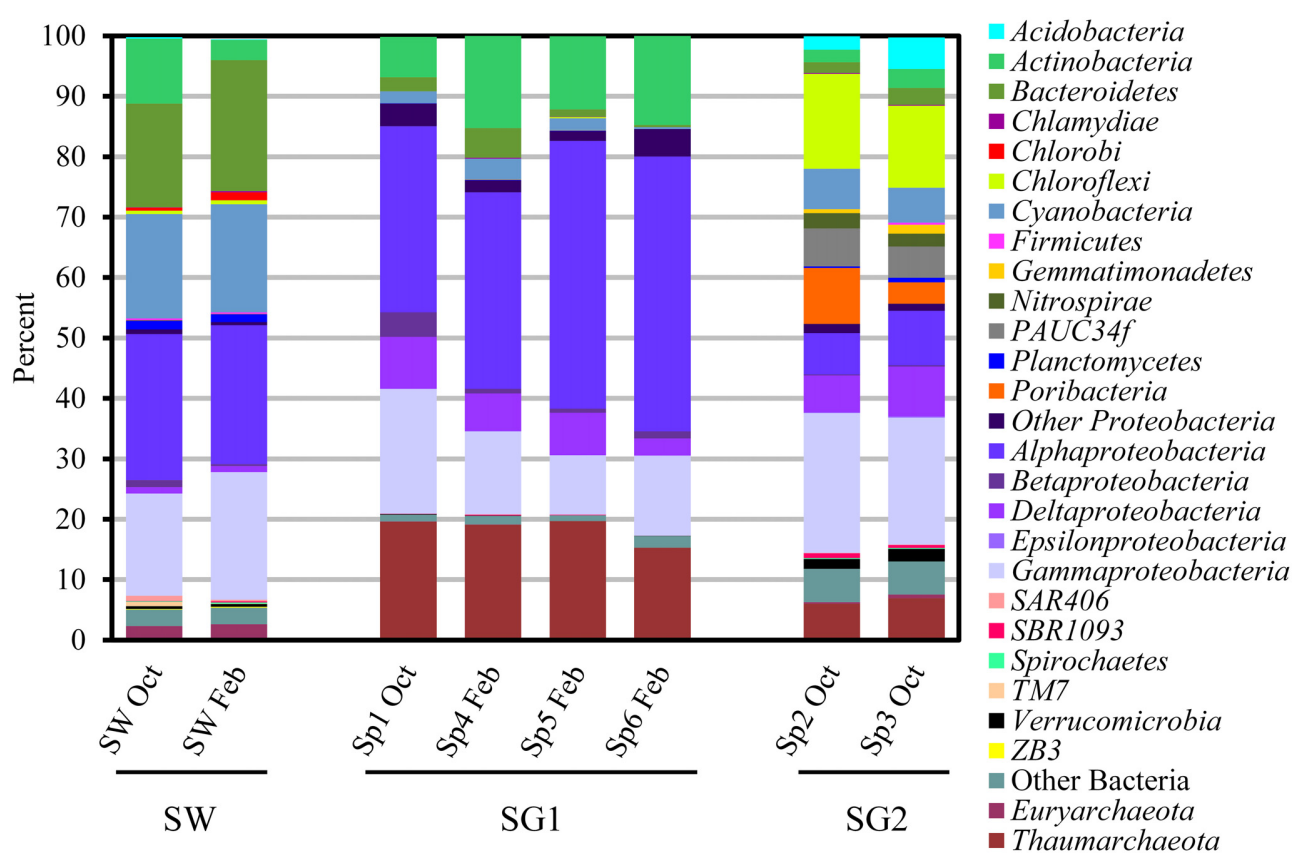

FIGURE 2 | Relative abundance of pyrosequencing reads at the phylum (or classes in the case of Proteobacteria) level present in six sponges (Sp1- 6: sponge 1- 6) and seawater (SW) samples collected in October 2011 (Oct) and February 2012 (Feb). Phyla comprised of $<0.1 \%$ of sequences per sample are not shown. Based on the microbial community structure, samples were placed into two groups: sponge group 1 (SG1: Sp1 Oct, Sp4 Feb, Sp5 Feb and Sp6 Feb) and sponge group 2 (SG2: Sp2 Oct and Sp3 Oct). samples harbored a more diverse community of microbes as measured by a mean Shannon-Wiener diversity index of 5.95 \pm 0.25 (s.e.m.) compared to $3.73 \pm 0.22$ in the SG1 community $(t=-6.8, P<0.01$; Table 2$)$. Further, SG2 contained taxa from 21 different bacterial phyla and candidate phyla and 2 archaeal phyla; SG1 contained about half that with 12 bacterial and candidate phyla, and 2 archaeal phyla.

Overall, both sponge groups were dominated by Proteobacteria (SG1: $63.5 \pm 2.9 \%$; SG2: $38.9 \pm 1.0 \%$ ), but Alphaproteobacteria were more abundant $(t=5.23, P<0.01)$ in SG1 $(38.3 \pm 3.8 \%)$ than in SG2 $(7.9 \pm 0.2 \%)$. Proteobacteria in SG2 were dominated by the Gammaproteobacteria (22.1 $\pm 1.1 \%$, Figure 2). Actinobacteria were also present in both sponge groups, but were in significantly greater numbers $(t=3.23, P<0.05)$ in SG1 $(12.2 \pm 2.0 \%$, Figure 2$)$ than SG2 (2.6 $\pm 0.6 \%$, Figure 2$).$ SG2 harbored the candidate phylum Poribacteria $(6.4 \pm 2.9 \%)$ that was first discovered from sponge tissues and can be widespread in these invertebrates (Fieseler et al., 2004; Lafi et al., 2009). In contrast Poribacteria was below the detection limit in SG1 $(t=-3.67, P<0.05$; Figure 2$)$.

Only a few bacterial phyla or classes were not significantly different in abundance between SG1 and SG2: Bacteroidetes $(t=-0.049, \quad P>0.05), \quad$ Chlamydiae $(t=-2.08 \quad P>0.1)$, Firmicutes $(t=-1.63, P>0.1)$, Beta- $(t=1.22, P>0.1)$, Delta- $(t=0.08, P>0.1)$, Gammaproteobacteria $(t=-2.23$, $P>0.05)$, and SAR406 $(t=-0.42, P>0.1$, Figure 2$)$. On the contrary, many phyla were present in SG2 at $>1 \%$ (mean), but in very low abundance $(<0.07 \%$ mean $)$ or below detection limits in SG1 and included: Acidobacteria $(t=-4.03, P<0.02)$, Chloroflexi $(t=-22.09, \quad P<0.001), \quad$ Gemmatimonadetes $(t=-4.154, P<0.02)$, Nitrospirae $(t=-18.01, P<0.001)$, PAUC34f $(t=-17.63, \quad P<0.001)$ and Verrucomicrobia $(t=-11.99, P<0.001$, Figure 2$)$.

In SG1, a few OTUs noticeably dominated the community and composed $>10.0 \%$ of all the sequences. These included one unclassified Alphaproteobacteria OTU (30.0 \pm $4.4 \%)$, one OTU in the Cenarchaeaceae family (18.3 $\pm 1.1 \%$; Supplementary Figure 3), and one unclassified Actinobacteria OTU $(11.9 \pm 2.0 \%)$. In SG2, none of the OTUs represented more than $10 \%$ of all the community.

Another striking difference in the communities was the relative abundance of archaeal sequences. Archaeal sequences represented a large portion $(18.5 \pm 1.1 \%)$ of all the sequences recovered from SG1 samples, but only $6.9 \pm 0.7 \%$ for SG2 samples $(t=9.23$, $P<0.01$; Figure 2). In SG1, one archaeal OTU in Cenarchaeaceae family (mentioned above) was dominant $(99.3 \pm 0.3 \%)$. In SG2, $68.2 \pm 15.0 \%$ of archaeal reads also fell into one Cenarchaeaceae family OTU, but this OTU was different from the main one in SG1. A small proportion $(5.8 \pm 2.3 \%)$ of the SG2 archaeal sequences were assigned to the phylum Thaumarchaeota, which was almost absent (except for three sequences) from SG1 $(t=$ $7.48, P<0.01)$. These data indicate that the sponges collected in our study, while physically reminiscent, in the same genus, and from the same environment harbor distinct enough microbial communities to warrant a re-evaluation of their phylogenetic relationship. 
SEAWATER ARCHAEAL AND BACTERIAL COMMUNITIES ARE DISTINCT FROM SPONGES'

In the overlying seawater, Proteobacteria (45.0 $\pm 0.9 \%)$ and particularly Alpha- $(23.6 \pm 0.6 \%)$ and Gamma- $(19.0 \pm$ $2.1 \%$ ) - were the most abundant taxa of bacteria. In addition, Bacteroidetes $(19.4 \pm 2.2 \%)$, Cyanobacteria $(17.6 \pm 0.3 \%)$, and Actinobacteria $(7.0 \pm 3.7 \%)$ were the only other bacterial phyla that comprised $>2 \%$ of all the reads.

The seawater-derived archaeal sequences represented $2.5 \pm$ $0.2 \%$ of sequences and mostly belonged to the Thaumarchaeota, in particular the Marine Group II or Marine Group III. Marine Group II represented $89.3 \pm 4.4 \%$ of all seawater archaeal sequences with a single OTU with pronounced dominance $(58.5 \pm 6.0 \%$; Supplementary Figure 2).

\section{CINACHYRELLA'S CORE AND VARIABLE MICROBIAL COMMUNITIES}

To further examine the distinct microbial communities, core and variable members of each group were compared. The numbers of common OTUs between SG1 and SG2 was relatively low, with only 95 shared OTUs representing $22.4 \%$ of the OTUs in SG2 and $30.5 \%$ in SG1. This was approximately equivalent to the numbers of OTUs the seawater shared with SG1 (94 OTUs) and SG2 (103 OTUs, Figure 3A).

Within each sponge group, 136 common OTUs were found in SG2 samples, as compared to 21 shared in the two SG1 samples (Figures 3B,C). In SG2, these common OTUs belonged to 2 archaeal and 14 bacterial phyla, with the most abundant being ( $\geq 8$ shared OTUs): Bacteroidetes, Chloroflexi, Cyanobacteria, and
Proteobacteria. Interestingly, the samples in SG2 also shared 12 unclassified bacterial OTUs. In SG1, the shared OTUs belonged to the Crenarchaeota, Actinobacteria, Bacteroidetes, Cyanobacteria and Proteobacteria. The diversity among sponge samples of the same group was similar at the class level, but not shared at the family or genus level. In most cases, many of the OTUs were present in only one of the sponge samples. Out of all the sponge samples, 83 OTUs were present in at least $50 \%$ of the samples and 23 OTUs in at least $70 \%$ of the sponge samples. Within SG1 and SG2, 107 and 424 OTUs respectively were present in at least 50\% of the samples and 55 and 135 OTUs respectively were present in at least $70 \%$ of the samples. The only 11 OTUs common to all the sponge samples (i.e., the core community) were assigned to the Proteobacteria (Alpha- and Gamma-) as well as Cyanobacteria, the Bacteroidetes and the Actinobacteria.

\section{MICROBIAL COMMUNITY FUNCTIONAL INSIGHTS}

QIIME analysis of the 16S rRNA gene sequences revealed that microbes with potential contribution to the nitrogen cycle were present. SG2 samples contained OTUs belonging to the genera Cenarchaeum (18.4 $\pm 12.1 \%$ of the archaeal reads) and Nitrosopumilus $(6.9 \pm 5.9 \%$ of archaeal reads). These genera are part of the ammonia-oxidizing archaea (AOA) that oxidize ammonia to nitrite (Preston et al., 1996; Walker et al., 2010). In SG1, AOA sequences belonging to the family Cenarchaeaceae were also present. Bacteria involved in the second step of nitrification, the oxidation of nitrite to nitrate were present in SG2 samples. These belonged to two OTUS in the family Nitrospiracea (phylum

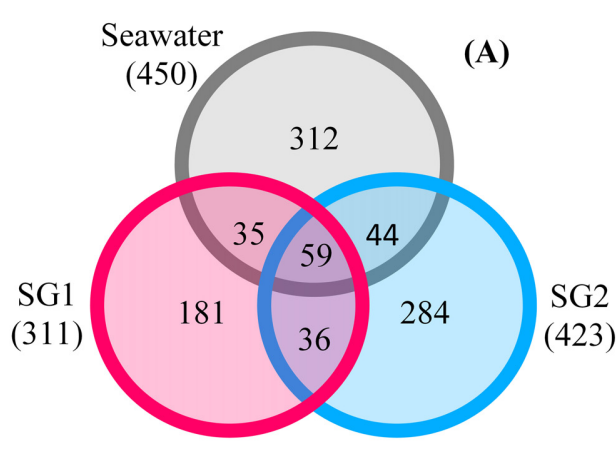

(B)

(219)

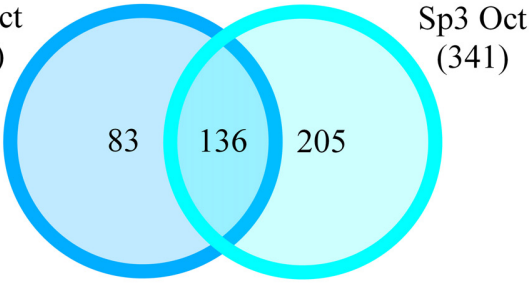

(C)

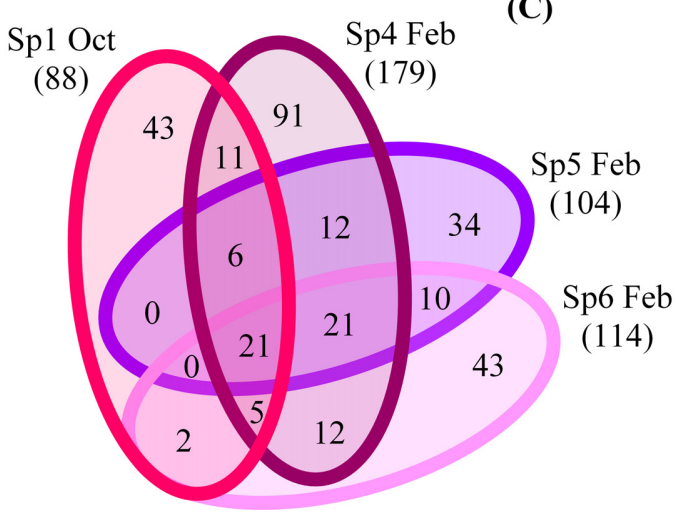

FIGURE 3 | Venn diagrams of specific and shared classified OTUs between. (A) Sponge group 1 (SG1)-SG2-seawater (SW); (B) SG1 samples; (C) SG2 samples. 
Nitrospirae, $2.3 \pm 0.2 \%$; Supplementary Figure 3) with $98.3 \pm$ $0.02 \%$ of these reads affiliated to one OTU. This OTU had $99 \%$ identity to sponge-derived sequences

In the Chloroflexi (which was almost absent from SG1), two classes were abundant in SG2: Anaerolinae $(7.4 \pm 1.6 \%)$ and SAR202 $(6.4 \pm 0.6 \%)$, with most OTUs in the latter class belonging to sponge-specific clusters.

The most abundant Cyanobacteria OTU in SG1 $(1.6 \% \pm$ $0.6 \%)$ and SG2 $(4.7 \% \pm 0.1 \%)$ was $100 \%$ identical to Synechoccocus strain WH8109. This also was the second most abundant OTU in seawater. One noteworthy finding related to Cyanobacteria involved the numerically dominant OTU in seawater, which was $100 \%$ identical to a UCYN-A clone, Candidatus Atelocyanobacterium thalassa (Thompson et al., 2012), a widespread cyanobacterium and likely a significant contributor to $\mathrm{N}_{2}$-fixation in marine waters (Zehr et al., 2001; Moisander et al., 2010).

In the phylum Proteobacteria, many OTUs were obtained that could not be further classified, but had little overlap between SG1 and SG2. In SG1, the unclassified sequences in each of the Proteobacteria class had one clear dominant OTU. In the Alpha-, Beta-, Delta- and Gammaproteobacteria sequences, this OTU encompassed $77.4 \pm 4.2 \%, 92.1 \pm 3.2 \%,>95.5 \pm 1.4 \%, 55.4 \pm$ $5.9 \%$ of the reads in each class, respectively. In contrast, in SG2, none of the unclassified OTU at the class level included more than $37.1 \pm 0.2 \%$ of the sequences and a few abundant OTUs were usually present. In all sponge samples, many unclassified OTUs (at the class level) were closely related to uncultured bacteria derived from sponge tissues. In particular, the most abundant unclassified Alpha- and Gammaproteobacteria OTUs were 99 and $100 \%$ identical, respectively, to a sequence from Cinachyra sp. from India. Within the classified Alphaproteobacteria, the families Rhodobacteraceae and Rhodospirillaceae were common and diverse in both sponge groups and seawater. As expected Pelagibacteraceae were the most abundant Alphaproteobacteria in the seawater.

\section{DISCUSSION}

Since our field collections were confined to a relatively small portion of the reef, we did not intend or expect to collect two apparently divergent Cinachyrella taxa. The sponges in this study were collected as part of a broader study involving greater number of specimens used for aquaculture. Upon analysis of the all the samples, it became clear that sponges formed two groups based on their microbial communities. The sponges in aquaculture (data not shown) were subject to different conditions. We therefore decided to present here only the data from sponges collected from the reef and never kept in aquaculture. In the present study, although we have confirmed that these specimens belong to the genus Cinachyrella, their exact taxonomic and phylogenetic identification goes beyond the scope of this paper, as the taxonomy of this genus and family (Tetillidae) is still under much debate (see introduction and Szitenberg et al., 2013). However, our findings are consistent, but not totally sufficient (due to low sample number and the low 28S rRNA sequence quality of two of our six samples) to prove the idea presented by Cárdenas et al. (2012) that microbiome signatures may be useful traits to delineate some sponge taxa. Thus, additional samples and a more comprehensive histology and electron microscopy analyses of the spicules would be needed to confirm the species identity of these sponge individuals. However, given the clear differences in the microbiomes of these sponge taxa, a simple PCR diagnostic of one or more variable members of the sponges' microbiota could also be used.

Overall, our results are similar to those of Chambers et al. (2013). There, the authors showed that two sponge morphs initially assigned to the genus Paratetilla (Demospongiae, Tetillidae) had different microbial communities, sharing less than $43 \%$ similarity. Within each morph group, microbial community similarity varied between 65 and $94 \%$ between individuals. Using COI gene, the authors confirmed that one of the sponge morphs actually belonged to the genus Cinachyrella, "challenging the value of the morphological characters used in the classification of these genera" (Chambers et al., 2013). Similar to our results, the bacterial communities were different for the two groups, even for specimens collected from the same location.

\section{DIVERSE MICROBES ARE PRESENT IN CINACHYRELLA}

Multiple studies have shown that marine sponges can harbor a large diversity of microbes and the microbial taxa richness present in our Cinachyrella tissue samples (90-341 OTUs) was within the range of other sponge species. An extensive study targeting 32 species from eight different locations worldwide revealed each sponge carried between 225 and 364 OTUs (at 97\% identity) with sequence coverage similar to our study (Schmitt et al., 2012). As expected, when sequencing depth was much greater, OTU richness was higher, reaching numbers between 1099 and 2996 OTUs (95\% identity) in three Pacific sponge species (Webster et al., 2010). Total taxon richness (at a higher sequencing depth) was also greater in C. australiensis sampled from the coast of Indonesia, in which 800 phylotypes were present (Cleary et al., 2013). In subtropical waters of Key Largo, FL, USA (close to our study site), the barrel sponge Xestospongia muta had Shannon diversity indices comparable to the lower range of our Cinachyrella samples (Montalvo and Hill, 2011). However, Cinachyrella contained fewer OTUs than Axinella corrugata (at least 1000 OTUs per specimen) collected less than a few miles away from our study site (White et al., 2012). Compared to the coral Orbicella faveolata (formerly Montastraea faveolata; Kimes et al., 2013), our sponge samples showed similar diversity, for which 943 bacterial clones contained 178 OTUs (97\% similarity threshold), with Chao 1 estimates of 307 ribotypes (Sunagawa et al., 2009). Similarly, the coral O. annularis sampled from various sites at Curaçao Island harbored 163-323 bacterial OTUs (Barott et al., 2011).

\section{CINACHYRELLA HARBOR FUNCTIONALLY DIVERSE MICROBES}

A small percentage of the bacterial 16S rRNA gene fragments could not be further classified indicating that some of the bacterial diversity remains unexplored. This number was much lower than those reported for A. corrugata collected nearby, in which $36 \%$ of the reads obtained by amplification of the $16 \mathrm{~S}$ rRNA gene V1-V3 regions were not assigned to any bacterial phylum (White et al., 2012). In their pyrosequencing study of C. australiensis and 
Suberites diversicolor microbiomes, Cleary et al. (2013) also found $34 \%$ of bacterial OTUs unclassified at the phylum level. There, the primers used targeted the V3-V4 regions while the V4 region was used for this Cinachyrella study.

In sponges, the dominant microbial phyla can vary with taxonomy and across geographical location or habitat. High microbial abundance (HMA) sponges usually harbor many bacterial taxa while low microbial abundance (LMA) sponges typically have one or few numerically dominant taxa and a few less abundant ones (Hentschel et al., 2003; Giles et al., 2013). In this study, SG1 samples contained few taxa with pronounced dominance, resembling LMA sponges in terms of microbial equitability, but also encompassed many other phylotypes, atypical of LMA sponges. SG2 samples clearly harbored a more diverse microbial community, similar to HMA sponges. It is important to note that the similarity of these sponge groups to HMA and LMA was inferred solely based on the structure of the microbiomes and an in-depth histological study was not performed on these samples to confirm microbial abundance.

SG2 samples contained the candidate phylum Poribacteria, but this taxon was below detection limits in both SG1 and seawater. This is notable because Poribacteria are typical members of sponge microbiomes, but have mostly been detected in HMA sponges (Hochmuth et al., 2010). This taxon can be diverse, as shown by Schmitt et al. (2012) who detected a total of 437 Poribacteria OTUs in the 32 sponges species studied, with up to 79 different Poribacteria OTUs (97\% identity) per species. In our Cinachyrella, Poribacteria were only classified as two OTUs. This lower diversity related to Poribacteria might be distinctive of Cinachyrella because only four OTUs were present in C. autraliensis specimens from open ocean habitats in Indonesia and similar to our SG1, Poribacteria were undetected in specimens collected from nearby marine lakes (Cleary et al., 2013).

Chloroflexi also was below detection limits in SG1. This again might be typical of LMA sponges as the Chloroflexi were absent in LMA sponges from the Red Sea, the Caribbean Sea and the South Pacific Ocean and present in low numbers in other LMA sponges (Schmitt et al., 2011; Giles et al., 2013). In SG2, Chloroflexi sequences were grouped into 12 OTUs, close to the range (1421 OTUs) Schmitt et al. (2011) reported for HMA sponges, but lower than the 502 OTUs (97\% identity) retrieved from another 32 sponge species (Schmitt et al., 2012).

Giles et al. (2013) studied the microbiomes in six species of LMA sponges using clone libraries and found that the phyla Acidobacteria, Chloroflexi and Gemmatimonadetes were not detected. Here, SG1 samples also were missing these phyla (with the exception of three sequences of SAR202-Chloroflexi and two sequences in the Gemmatimonadetes). These three bacterial phyla were also missing in eight of the 13 species analyzed by Jeong et al. (2013). The other five species contained a high microbial diversity with a large proportion of Chloroflexi (this group was called the CF group because of the Chloroflexi).

We also found a large portion of unclassified Proteobacteria in the sponge, but not in the seawater suggesting that it was not a consequence of the analysis. In the sponges Raspailia ramosa and Stelligera stuposa, 32 and $17 \%$ of the Proteobacteria sequences, respectively, were unclassified as opposed to only $1 \%$ in the seawater (Jackson et al., 2012). Further exploration suggests that many of our unclassified Proteobacteria OTUs are spongespecific and the presence of large clusters of sponge-specific and sponge- and coral-specific bacteria in the invertebrates have been described (Simister et al., 2012). Interestingly, our results related to Proteobacteria were similar to Cleary et al. (2013). In their study, Alphaproteobacteria were more abundant in C. australiensis from marine lakes than open ocean habitats. In our Cinachyrella samples, Alphaproteobacteria were significantly more abundant in the SG1 than SG2. These might again be typical of some LMA sponges as Kamke et al. (2010) also recovered a large portion of Alphaproteobacteria clones from LMA sponges.

Cinachyrella symbionts also belonged to the Archaea (6.9$18.5 \%)$, in proportions within the wide range recorded for four deep water (4-65\%) and three shallow water sponges from the Red Sea (4-28\%) (Lee et al., 2011; Kennedy et al., 2014). All of the archaeal sequences in Cinachyrella fell within two phyla: Thaumarchaeota and Euryarchaeota, with most of the archaea belonging to the Thaumarchaeota, which is widespread in sponges (Webster et al., 2001; Margot et al., 2002; Lee et al., 2011; Kennedy et al., 2014; Polónia et al., 2014). Archaeal reads grouped into a low number of OTUs, with a few numerically dominant ones, similar to the four species sampled by Kennedy et al. (2014), which had $70 \%$ of the Thaumarchaeota sequences separated in three OTUs. The phylum Thaumarchaeota includes AOA performing the first step of nitrification using ammonium excreted by sponges as a metabolic waste product (Jiménez and Ribes, 2007; Bayer et al., 2008; Hoffmann et al., 2009). Ammonia oxidation by archaea is believed to be widespread in marine environments (Francis et al., 2005; Könneke et al., 2005; Schleper et al., 2005) and was detected both the LMA and HMA sponges (Schläppy et al., 2010). In addition to the AOA, nitrite-oxidizing bacteria catalyzing the second step of nitrification were found in SG2. Hentschel et al. (2002) detected early on clones affiliated with nitrite-oxidizing phylum Nitrospirae in sponges. The proportion of this phylum varies greatly between host species, ranging from $0.6 \%$ in $X$. testudinaria from the Red Sea (Lee et al., 2011 ) to $24 \%$ in Stelligera stuposa from Irish waters (Jackson et al., 2012). Overall, in the present study, it appears that only one group of Cinachyrella (SG2) harbors the microbes required for both steps of nitrification.

\section{THE TWO SPONGE GROUPS ONLY SHARE A SMALL CORE MICROBIOME}

Symbionts in SG1 and SG2 were very different at the OTU level with both groups only sharing a small core microbial community as seen in many sponges. For example, C. australiensis from open ocean habitat and marine lakes only shared $9.4 \%$ of their OTUs (Cleary et al., 2013), lower than the percentage shared between SG1 and SG2. In contrast, the sponge genus Xestospongia often showed exceptionally high overlap in OTUs. For example, X. muta (collected from Florida) and X. testudinaria (from Indonesia) shared $85 \%$ of the reads (=245 OTUs) between the two species (Montalvo et al., 2014). However, after surveying 32 sponge species, Schmitt et al. (2012) concluded that phylogeny of the host (i.e., how closely related sponges were) did not correlate with the bacterial composition. Similarly, host sponge 
phylogeny-except for the genus Xestospongia-did not affect the similarity of the symbionts communities in sponges from Orpheus Island (Webster et al., 2013). Nevertheless, when triplicate individuals of the same species (including Cinachyra sp.) were analyzed, conserved ( $>65 \%$ similarity) microbial communities were observed (Webster et al., 2013). This is consistent with the pyrosequencing characterization of $A$. corrugata symbiont communities in S. Florida (White et al., 2012), which showed relatively high similarities among multiple individuals and across hundreds of $\mathrm{km}$. In Cinachyrella, the numbers of shared OTUs between SG1 samples (12-24\%) and SG2 samples (39-62\%) was low. Giles et al. (2013) and Schmitt et al. (2012) suggest environmental factors such as temperature, salinity or nutrient levels might impact symbionts population structures. In their study, species from tropical waters had more similar bacterial communities. This did not hold true at a smaller scale as we observed distinct communities in the two sponge groups from the same environment, independent of spatial or temporal scales.

Considering many sponges (including Cinachyrella) have a reduced core and large variable microbial community, it would be reasonable to assume that different OTUs perform distinct functions within the sponge. However, using a metagenomic approach, a recent study showed that taxonomically divergent sponges can harbor phylogenetically diverse symbionts with functional equivalence (Fan et al., 2012). The authors were able to show that six sponge species possess similar functional profiles distinct from the ones obtained for the seawater microbial communities (Fan et al., 2012). These findings suggest that key functions in marine sponges might be performed by different microbial taxa and a phylogenetically similar "core microbial community" may therefore not be essential to meet the sponge requirements. Moreover, perhaps the concept of a "core" microbiome, for Porifera at least, may have to be redefined altogether to emphasize function over symbiont identity. This view may not be so far fetched when considering that bacteria can often drastically change their metabolic activities through horizontal gene transfers (Costa et al., 2009).

Together with recent and ongoing molecular microbiome analyses of adjacent coastal waters and reef invertebrate hosts (unpublished), this study contributes to a growing spatiotemporal profile of microbiome dynamics in subtropical South Florida (Negandhi et al., 2010; White et al., 2012). These results also help provide a baseline characterization for Cinachyrella, which may be developed for further experimental studies, due to its hardiness in aquaculture, relative ease of collection and maintenance.

\section{AUTHOR CONTRIBUTIONS}

Marie L. Cuvelier, Emily Blake, Rebecca L. Vega Thurber, Peter J. McCarthy, and Jose V. Lopez designed research; Marie L. Cuvelier, Emily Blake, and Jose V. Lopez performed sampling; Marie L. Cuvelier performed DNA extractions and 16S rRNA amplicon preparation; Emily Blake performed sponge taxonomy analysis; Rebecca Mulheron performed 28S rRNA PCR; Marie L. Cuvelier, Rebecca L. Vega Thurber, and Jose V. Lopez analyzed data; Marie L. Cuvelier, Emily Blake, Peter J. McCarthy, Patricia Blackwelder, Rebecca L. Vega Thurber, and Jose V. Lopez wrote the paper.
Funding was awarded to Jose V. Lopez, Rebecca L. Vega Thurber, Peter J. McCarthy, and Patricia Blackwelder.

\section{ACKNOWLEDGMENTS}

This work was supported by a Year 1 BP Gulf of Mexico Research Initiative grant to the Florida Institute of Oceanography. Therefore, data has been uploaded to the Gulf of Mexico Research Initiative data portal-https://data.gulfresearchinitiative.org. Molecular phylogeny of sponges was supported by the National Science Foundation's "Assembling the Porifera Tree of Life" (PorToL.org) grant DEB-0820791 to JVL. Any opinions, findings, and conclusions or recommendations expressed in this material are those of the authors and do not necessarily reflect the views of the National Science Foundation. We thank Alexandra Campbell, Ari Halperin, Dawn Formica, Ian Rodericks, Katy Brown, Keri O’Neal, Megan Zappe, Peter Grasso, Rory Welsh, Captain Lance Robinson and Assistant Harbor Master Brian Buskirk for assistance with the SCUBA diving and sample collections and processing. We thank Dr. Robert Thacker, Dr. Paco Cárdenas, Dr. Cristina Díaz and other PorToL members for assistance with the Cinachyrella taxonomy. We also thank Dr. Jesse Zaneveld, Dr. Dana Wilson for constructive discussion on the data analysis. This is Harbor Branch Oceanographic Institute contribution number 1940. 28S rRNA sequences have been deposited in GenBank under accession no. KM588360 through 588363. $16 \mathrm{~S}$ rRNA sequences have been deposited in NCBI SRA under accession no. SRP047337.

\section{SUPPLEMENTARY MATERIAL}

The Supplementary Material for this article can be found online at: http://www.frontiersin.org/journal/10.3389/fmicb.2014. 00581/abstract

\section{Supplementary Figure 1 | Rarefaction curves (note: SW Feb is under the Sp6 Feb line).}

Supplementary Figure 2 | PCoA analysis of weighted UniFrac distance. UniFrac measure phylogenetic distances between OTUs sets within a phylogenetic tree. Here, we used weighted UniFrac, which takes into account relative abundances of OTUs (as opposed to presence/absence only). 64 sponge individuals were used in total and Sp1 through Sp6 are labeled.

Supplementary Figure 3 | Number of OTUs, abundance and classification of all the sequences present in the seawater (Oct and Feb), Sponge Group 1 (Sp1 Oct, Sp4 Feb, Sp5 Feb, Sp6 Feb) and Sponge Group 2 (Sp2 Oct and Sp3 Oct). Each OTU is classified at the lowest ranking.

\section{REFERENCES}

Barott, K. L., Rodriguez-Brito, B., Janouškovec, J., Marhaver, K. L., Smith, J. E., Keeling, P., et al. (2011). Microbial diversity associated with four functional groups of benthic reef algae and the reef-building coral Montastraea annularis. Environ. Microbiol. 13, 1192-1204. doi: 10.1111/j.1462-2920.2010.02419.x

Bates, S. T., Berg-Lyons, D., Caporaso, J. G., Walters, W. A., Knight, R., and Fierer, N. (2011). Examining the global distribution of dominant archaeal populations in soil. ISME J. 5, 908-917. doi: 10.1038/ismej.2010.171

Bayer, K., Schmitt, S., and Hentschel, U. (2008). Physiology, phylogeny and in situ evidence for bacterial and archaeal nitrifiers in the marine sponge Aplysina aerophoba. Environ. Microbiol. 10, 2942-2955. doi: 10.1111/j.14622920.2008.01582.x

Caporaso, J. G., Bittinger, K., Bushman, F. D., DeSantis, T. Z., Andersen, G. L., and Knight, R. (2010a). PyNAST: a flexible tool for aligning sequences to a 
template alignment. Bioinformatics 26, 266-267. doi: 10.1093/bioinformatics/ btp636

Caporaso, J. G., Kuczynski, J., Stombaugh, J., Bittinger, K., Bushman, F. D., Costello, E. K., et al. (2010b). QIIME allows analysis of high-throughput community sequencing data. Nat. Methods 7, 335-336. doi: 10.1038/nmeth.f.303

Caporaso, J. G., Lauber, C. L., Walters, W. A., Berg-Lyons, D., Lozupone, C. A., Turnbaugh, P. J., et al. (2011). Global patterns of 16 S rRNA diversity at a depth of millions of sequences per sample. Proc. Natl. Acad. Sci. U.S.A. 108(Suppl. 1), 4516-4522. doi: 10.1073/pnas.1000080107

Cárdenas, P., Menegola, C., Rapp, H. T., and Díaz, M. C. (2009). Morphological description and DNA barcodes of shallow-water Tetractinellida (Porifera: Demospongiae) from Bocas del Toro, Panama, with description of a new species. Zootaxa 2276, 1-39. Available online at: http://www.mapress.com/zootaxa/list/ 2009/zt02276.html

Cárdenas, P., Pérez, T., and Boury-Esnault, N. (2012). "Chapter two-sponge systematics facing new challenges," in Advances in Marine Biology Advances in Sponge Science: Phylogeny, Systematics, Ecology, eds M. A. Becerro, M. J. Uriz, M. Maldonado, and X. Turon (London, UK: Academic Press), 79-209.

Chambers, K., Padovan, A., Alvarez, B., and Gibb, K. (2013). Microbial signatures can help distinguish moon sponges (family Tetillidae) from Darwin Harbour, Australia. Mar. Freshwater Res. 64, 716-725. doi: 10.1071/MF12226

Cleary, D. F. R., Becking, L. E., de Voogd, N. J., Pires, A. C. C., Polónia, A. R. M., Egas, C., et al. (2013). Habitat- and host-related variation in sponge bacterial symbiont communities in Indonesian waters. FEMS Microbiol. Ecol. 85, 465-482. doi: 10.1111/1574-6941.12135

Costa, R., Van Aarle, I. M., Mendes, R., and Van Elsas, J. D. (2009). Genomics of pyrrolnitrin biosynthetic loci: evidence for conservation and whole-operon mobility within Gram-negative bacteria. Environ. Microbiol. 11, 159-175. doi: 10.1111/j.1462-2920.2008.01750.x

de Goeij, J. M., van Oevelen, D., Vermeij, M. J. A., Osinga, R., Middelburg, J. J., Goeij, A. F. P. M., et al. (2013). Surviving in a marine desert: the sponge loop retains resources within coral reefs. Science 342, 108-110. doi: 10.1126/science. 1241981

Díaz, M. C., and Rützler, K. (2001). Sponges: an essential component of Caribbean coral reefs. Bull. Mar. Sci. 69, 535-546. Available online at: http://www.ingentaconnect.com/content/umrsmas/bullmar/2001/00000069/00000002/art00026

Edgar, R. C. (2010). Search and clustering orders of magnitude faster than BLAST. Bioinformatics 26, 2460-2461. doi: 10.1093/bioinformatics/btq461

Fan, L., Reynolds, D., Liu, M., Stark, M., Kjelleberg, S., Webster, N. S., et al. (2012). Functional equivalence and evolutionary convergence in complex communities of microbial sponge symbionts. Proc. Natl. Acad. Sci. U.S.A. 109, E1878-E1887. doi: 10.1073/pnas.1203287109

Fieseler, L., Horn, M., Wagner, M., and Hentschel, U. (2004). Discovery of the novel candidate phylum "Poribacteria" in marine sponges. Appl. Environ. Microbiol. 70, 3724-3732. doi: 10.1128/AEM.70.6.3724-3732.2004

Francis, C. A., Roberts, K. J., Beman, J. M., Santoro, A. E., and Oakley, B. B. (2005). Ubiquity and diversity of ammonia-oxidizing archaea in water columns and sediments of the ocean. Proc. Natl. Acad. Sci. U.S.A. 102, 14683-14688. doi: 10.1073/pnas.0506625102

Giles, E. C., Kamke, J., Moitinho-Silva, L., Taylor, M. W., Hentschel, U., Ravasi, T., et al. (2013). Bacterial community profiles in low microbial abundance sponges. FEMS Microbiol. Ecol. 83, 232-241. doi: 10.1111/j.1574-6941.2012. 01467.x

Haas, B. J., Gevers, D., Earl, A. M., Feldgarden, M., Ward, D. V., Giannoukos, G., et al. (2011). Chimeric 16S rRNA sequence formation and detection in Sanger and 454-pyrosequenced PCR amplicons. Genome Res. 21, 494-504. doi: 10.1101/gr.112730.110

Hentschel, U., Fieseler, L., Wehrl, M., Gernert, C., Steinert, M., Hacker, J., et al. (2003). Microbial diversity of marine sponges. Prog. Mol. Subcell. Biol. 37, 59-88. doi: 10.1007/978-3-642-55519-0_3

Hentschel, U., Hopke, J., Horn, M., Friedrich, A. B., Wagner, M., Hacker, J., et al. (2002). Molecular evidence for a uniform microbial community in sponges from different oceans. Appl. Environ. Microbiol. 68, 4431-4440. doi: 10.1128/AEM.68.9.4431-4440.2002

Hentschel, U., Usher, K. M., and Taylor, M. W. (2006). Marine sponges as microbial fermenters. FEMS Microbiol. Ecol. 55, 167-177. doi: 10.1111/j.15746941.2005.00046.x

Hochmuth, T., Niederkrüger, H., Gernert, C., Siegl, A., Taudien, S., Platzer, M., et al. (2010). Linking chemical and microbial diversity in marine sponges: possible role for Poribacteria as producers of methyl-branched fatty acids. Chembiochem 11, 2572-2578. doi: 10.1002/cbic.201000510

Hoffmann, F., Larsen, O., Thiel, V., Rapp, H. T., Pape, T., Michaelis, W., et al. (2005). An anaerobic world in sponges. Geomicrobiol. J. 22, 1-10. doi: 10.1080/01490450590922505

Hoffmann, F., Radax, R., Woebken, D., Holtappels, M., Lavik, G., Rapp, H. T., et al. (2009). Complex nitrogen cycling in the sponge Geodia barretti. Environ. Microbiol. 11, 2228-2243. doi: 10.1111/j.1462-2920.2009.01944.x

Hugenholtz, P., Goebel, B. M., and Pace, N. R. (1998). Impact of cultureindependent studies on the emerging phylogenetic view of bacterial diversity. J. Bacteriol. 180, 6793-6793.

Ilan, M., Gugel, J., and van Soest, R. (2004). Taxonomy, reproduction and ecology of new and known Red Sea sponges. Sarsia 89, 388-410. doi: $10.1080 / 00364820410002659$

Jackson, S. A., Kennedy, J., Morrissey, J. P., O’Gara, F., and Dobson, A. D. W. (2012). Pyrosequencing reveals diverse and distinct sponge-specific microbial communities in sponges from a single geographical location in Irish waters. Microb. Ecol. 64, 105-116. doi: 10.1007/s00248-011-0002-x

Jeong, I.-H., Kim, K.-H., and Park, J.-S. (2013). Analysis of bacterial diversity in sponges collected off Chujado, an Island in Korea, using barcoded 454 pyrosequencing: analysis of a distinctive sponge group containing Chloroflexi. J. Microbiol. 51, 570-577. doi: 10.1007/s12275-013-3426-9

Jiménez, E., and Ribes, M. (2007). Sponges as a source of dissolved inorganic nitrogen: Nitrification mediated by temperate sponges. Limnol. Oceanogr. 52, 948-958. doi: 10.4319/lo.2007.52.3.0948

Kamke, J., Taylor, M. W., and Schmitt, S. (2010). Activity profiles for marine sponge-associated bacteria obtained by $16 \mathrm{~S}$ rRNA vs $16 \mathrm{~S}$ rRNA gene comparisons. ISME J. 4, 498-508. doi: 10.1038/ismej.2009.143

Kennedy, J., Flemer, B., Jackson, S. A., Morrissey, J. P., O'Gara, F., and Dobson, A. D. W. (2014). Evidence of a putative deep sea specific microbiome in marine sponges. PLoS ONE 9:e91092. doi: 10.1371/journal.pone.00 91092

Kimes, N. E., Johnson, W. R., Torralba, M., Nelson, K. E., Weil, E., and Morris, P. J. (2013). The Montastraea faveolata microbiome: ecological and temporal influences on a Caribbean reef-building coral in decline. Environ. Microbiol. 15, 2082-2094. doi: 10.1111/1462-2920.12130

Könneke, M., Bernhard, A. E., de la Torre, J. R., Walker, C. B., Waterbury, J. B., and Stahl, D. A. (2005). Isolation of an autotrophic ammonia-oxidizing marine archaeon. Nature 437, 543-546. doi: 10.1038/nature03911

Lafi, F. F., Fuerst, J. A., Fieseler, L., Engels, C., Goh, W. W. L., and Hentschel, U. (2009). Widespread distribution of Poribacteria in Demospongiae. Appl. Environ. Microbiol. 75, 5695-5699. doi: 10.1128/AEM.00035-09

Lane, D. (1991). “16S/23S rRNA sequencing," in Nucleic Acid Techniques in Bacterial Systematics, eds E. Stackebrandt and M. Goodfellow (West Sussex: John Wiley and Sons), 115-175.

Lee, O. O., Wang, Y., Yang, J., Lafi, F. F., Al-Suwailem, A., and Qian, P.-Y. (2011). Pyrosequencing reveals highly diverse and species-specific microbial communities in sponges from the Red Sea. ISME J. 5, 650-664. doi: 10.1038/ismej.2010.165

Li, C.-W., Chen, J.-Y., and Hua, T.-E. (1998). Precambrian sponges with cellular structures. Science 279, 879-882. doi: 10.1126/science.279.53 52.879

Lozupone, C., and Knight, R. (2005). UniFrac: a new phylogenetic method for comparing microbial communities. Appl. Environ. Microbiol. 71, 8228-8235. doi: 10.1128/AEM.71.12.8228-8235.2005

Margot, H., Acebal, C., Toril, E., Amils, R., and Puentes, J. F. (2002). Consistent association of crenarchaeal Archaea with sponges of the genus Axinella. Mar. Biol. 140, 739-745. doi: 10.1007/s00227-001-0740-2

McDonald, D., Price, M. N., Goodrich, J., Nawrocki, E. P., DeSantis, T. Z., Probst, A., et al. (2012). An improved Greengenes taxonomy with explicit ranks for ecological and evolutionary analyses of bacteria and archaea. ISME J. 6, 610-618. doi: 10.1038/ismej.2011.139

Mohamed, N. M., Saito, K., Tal, Y., and Hill, R. T. (2010). Diversity of aerobic and anaerobic ammonia-oxidizing bacteria in marine sponges. ISME J. 4, 38-48. doi: 10.1038/ismej.2009.84

Moisander, P. H., Beinart, R. A., Hewson, I., White, A. E., Johnson, K. S., Carlson, C. A., et al. (2010). Unicellular cyanobacterial distributions broaden the oceanic N2 fixation domain. Science 327, 1512-1514. doi: 10.1126/science. 1185468 
Montalvo, N. F., Davis, J., Vicente, J., Pittiglio, R., Ravel, J., and Hill, R. T. (2014). Integration of culture-based and molecular analysis of a complex sponge-associated bacterial community. PLoS ONE 9:e90517. doi: 10.1371/journal.pone.0090517

Montalvo, N. F., and Hill, R. T. (2011). Sponge-associated bacteria are strictly maintained in two closely related but geographically distant sponge hosts. Appl. Environ. Microbiol. 77, 7207-7216. doi: 10.1128/AEM.05 285-11

Negandhi, K., Blackwelder, P. L., Ereskovsky, A. V., and Lopez, J. V. (2010). Florida reef sponges harbor coral disease-associated microbes. Symbiosis 51, 117-129. doi: 10.1007/s13199-010-0059-1

Polónia, A. R. M., Cleary, D. F. R., Duarte, L. N., de Voogd, N. J., and Gomes, N. C. M. (2014). Composition of Archaea in seawater, sediment, and sponges in the kepulauan seribu reef system, Indonesia. Microb. Ecol. 67, 553-567. doi: 10.1007/s00248-013-0365-2

Preston, C. M., Wu, K. Y., Molinski, T. F., and DeLong, E. F. (1996). A psychrophilic crenarchaeon inhabits a marine sponge: Cenarchaeum symbiosum gen. nov., sp. nov. Proc. Natl. Acad. Sci. U.S.A. 93, 6241-6246. doi: 10.1073/pnas.93. 13.6241

Price, M. N., Dehal, P. S., and Arkin, A. P. (2010). FastTree 2 - approximately maximum-likelihood trees for large alignments. PLoS ONE 5:e9490. doi: 10.1371/journal.pone.0009490

Reeder, J., and Knight, R. (2010). Rapidly denoising pyrosequencing amplicon reads by exploiting rank-abundance distributions. Nat. Methods 7, 668-669. doi: 10.1038/nmeth0910-668b

Rützler, K., and Smith, K. (1992). Guide to western Atlantic species of cinachyrella (Porifera: Tetillidae). Proc. Biol. Soc. Wash. 105, 148-164.

Ryan, J. F., Pang, K., Schnitzler, C. E., Nguyen, A.-D., Moreland, R. T., Simmons, D. K., et al. (2013). The genome of the Ctenophore Mnemiopsis leidyi and its implications for cell type evolution. Science 342:1242592. doi: 10.1126/science. 1242592

Schläppy, M.-L., Schöttner, S. I., Lavik, G., Kuypers, M. M. M., de Beer, D., and Hoffmann, F. (2010). Evidence of nitrification and denitrification in high and low microbial abundance sponges. Mar. Biol. 157, 593-602. doi: 10.1007/s00227-009-1344-5

Schleper, C., Jurgens, G., and Jonuscheit, M. (2005). Genomic studies of uncultivated archaea. Nat. Rev. Microbiol. 3, 479-488. doi: 10.1038/ nrmicrol159

Schmitt, S., Deines, P., Behnam, F., Wagner, M., and Taylor, M. W. (2011). Chloroflexi bacteria are more diverse, abundant, and similar in high than in low microbial abundance sponges. FEMS Microbiol. Ecol. 78, 497-510. doi: 10.1111/j.1574-6941.2011.01179.x

Schmitt, S., Tsai, P., Bell, J., Fromont, J., Ilan, M., Lindquist, N., et al. (2012). Assessing the complex sponge microbiota: core, variable and speciesspecific bacterial communities in marine sponges. ISME J. 6, 564-576. doi: 10.1038/ismej.2011.116

Simister, R. L., Deines, P., Botté, E. S., Webster, N. S., and Taylor, M. W. (2012). Sponge-specific clusters revisited: a comprehensive phylogeny of sponge-associated microorganisms. Environ. Microbiol. 14, 517-524. doi: 10.1111/j.1462-2920.2011.02664.x

Sipkema, D., Holmes, B., Nichols, S. A., and Blanch, H. W. (2009) Biological characterisation of Haliclona (?gellius) sp.: sponge and associated microorganisms. Microb. Ecol. 58, 903-920. doi: 10.1007/s00248-0099534-8

Sollas, W. (1886). Preliminary account of the Tetractinellid sponges Dredged by H.M.S. "Challenger" 1872-76. Part I. The Choristida. Sci. Proc. R. Dublin Soc. 5, 177-199.

Steger, D., Ettinger-Epstein, P., Whalan, S., Hentschel, U., De Nys, R., Wagner, M. et al. (2008). Diversity and mode of transmission of ammonia-oxidizing archaea in marine sponges. Environ. Microbiol. 10, 1087-1094. doi: 10.1111/j.14622920.2007.01515.x

Sunagawa, S., DeSantis, T. Z., Piceno, Y. M., Brodie, E. L., DeSalvo, M. K., Voolstra, C. R., et al. (2009). Bacterial diversity and White Plague Disease-associated community changes in the Caribbean coral Montastraea faveolata. ISME J. 3, 512-521. doi: 10.1038/ismej.2008.131

Szitenberg, A., Becking, L. E., Vargas, S., Fernandez, J. C. C., Santodomingo, N., Wörheide, G., et al. (2013). Phylogeny of Tetillidae (Porifera, Demospongiae, Spirophorida) based on three molecular markers. Mol. Phylogenet. Evol. 67, 509-519. doi: 10.1016/j.ympev.2013.02.018
Taylor, M. W., Hill, R. T., Piel, J., Thacker, R. W., and Hentschel, U. (2007a). Soaking it up: the complex lives of marine sponges and their microbial associates. ISME J. 1, 187-190. doi: 10.1038/ismej.2007.32

Taylor, M. W., Radax, R., Steger, D., and Wagner, M. (2007b). Sponge-associated microorganisms: evolution, ecology, and biotechnological potential. Microbiol. Mol. Biol. Rev. 71, 295-347. doi: 10.1128/MMBR.00040-06

Thacker, R. W., Hill, A. L., Hill, M. S., Redmond, N. E., Collins, A. G., Morrow, C. C., et al. (2013). Nearly complete $28 \mathrm{~S}$ rRNA gene sequences confirm new hypotheses of sponge evolution. Integr. Comp. Biol. 53, 373-387. doi: 10.1093/icb/ict071

Thompson, A. W., Foster, R. A., Krupke, A., Carter, B. J., Musat, N., Vaulot, D., et al. (2012). Unicellular cyanobacterium symbiotic with a single-celled eukaryotic alga. Science 337, 1546-1550. doi: 10.1126/science.1222700

van Soest, R. W. M., Boury-Esnault, N., Hooper, J. N. A., Rützler, K., De Voogd, N. J., Alvarez de Glasby, B., et al. (2014). World Porifera Database. Available online at: http://www.marinespecies.org/porifera (Accessed May 09, 2014).

van Soest, R. W. M., Boury-Esnault, N., Vacelet, J., Dohrmann, M., Erpenbeck, D., De Voogd, N. J., et al. (2012). Global diversity of sponges (Porifera). PLoS ONE 7:e35105. doi: 10.1371/journal.pone.0035105

Vogel, S. (1977). Current-induced flow through living sponges in nature. Proc. Natl. Acad. Sci. U.S.A. 74, 2069-2071. doi: 10.1073/pnas.74.5.2069

Walker, B. K. (2012). Spatial analyses of benthic habitats to define coral reef ecosystem regions and potential biogeographic boundaries along a latitudinal gradient. PLoS ONE 7:e30466. doi: 10.1371/journal.pone.0030466

Walker, C. B., de la Torre, J. R., Klotz, M. G., Urakawa, H., Pinel, N., Arp, D. J., et al. (2010). Nitrosopumilus maritimus genome reveals unique mechanisms for nitrification and autotrophy in globally distributed marine crenarchaea. Proc. Natl. Acad. Sci. U.S.A. 107, 8818-8823. doi: 10.1073/pnas.0913 533107

Wang, Q., Garrity, G. M., Tiedje, J. M., and Cole, J. R. (2007). Naïve bayesian classifier for rapid assignment of rRNA sequences into the new bacterial taxonomy. Appl. Environ. Microbiol. 73, 5261-5267. doi: 10.1128/AEM.00 062-07

Webster, N. S., and Blackall, L. L. (2009). What do we really know about spongemicrobial symbioses? ISME J. 3, 1-3. doi: 10.1038/ismej.2008.102

Webster, N. S., Cobb, R. E., and Negri, A. P. (2008). Temperature thresholds for bacterial symbiosis with a sponge. ISME J. 2, 830-842. doi: 10.1038/ismej. 2008.42

Webster, N. S., Cobb, R. E., Soo, R., Anthony, S. L., Battershill, C. N., Whalan, S., et al. (2011). Bacterial community dynamics in the marine sponge Rhopaloeides odorabile under in situ and ex situ cultivation. Mar. Biotechnol. 13, 296-304. doi: 10.1007/s10126-010-9300-4

Webster, N. S., Luter, H. M., Soo, R. M., Botté, E. S., Simister, R. L., Abdo, D., et al. (2013). Same, same but different: symbiotic bacterial associations in GBR sponges. Front. Microbiol. 3:444. doi: 10.3389/fmicb.2012.00444

Webster, N. S., and Taylor, M. W. (2012). Marine sponges and their microbial symbionts: love and other relationships. Environ. Microbiol. 14, 335-346. doi: 10.1111/j.1462-2920.2011.02460.x

Webster, N. S., Taylor, M. W., Behnam, F., Lücker, S., Rattei, T., Whalan, S., et al. (2010). Deep sequencing reveals exceptional diversity and modes of transmission for bacterial sponge symbionts. Environ. Microbiol. 12, 2070-2082. doi: 10.1111/j.1462-2920.2009.02065.x

Webster, N. S., Watts, J. E. M., and Hill, R. T. (2001). Detection and phylogenetic analysis of novel crenarchaeote and euryarchaeote 16S ribosomal RNA gene sequences from a great barrier reef sponge. Mar. Biotechnol. 3, 600-608. doi: 10.1007/s10126-001-0065-7

White, J. R., Patel, J., Ottesen, A., Arce, G., Blackwelder, P., and Lopez, J. V. (2012). Pyrosequencing of bacterial symbionts within Axinella corrugata sponges: diversity and seasonal variability. PLOS ONE 7:e38204. doi: 10.1371/journal.pone.0038204

Wilkinson, C. R. (1978a). Microbial associations in sponges. I. Ecology, physiology and microbial populations of coral reef sponges. Mar. Biol. 49, 161-167. doi: 10.1007/BF00387115

Wilkinson, C. R. (1978b). Microbial associations in sponges. II. Numerical analysis of sponge and water bacterial populations. Mar. Biol. 49, 169-176. doi: 10.1007/BF00387116

Wilkinson, C. R. (1978c). Microbial associations in sponges. III. Ultrastructure of the in situ associations in coral reef sponges. Mar. Biol. 49, 177-185. doi: 10.1007/BF00387117 
Wilkinson, C. R., and Fay, P. (1979). Nitrogen fixation in coral reef sponges with symbiotic cyanobacteria. Nature 279, 527-529. doi: 10.1038/27 $9527 \mathrm{a} 0$

Zehr, J. P., Waterbury, J. B., Turner, P. J., Montoya, J. P., Omoregie, E., Steward, G. F., et al. (2001). Unicellular cyanobacteria fix $\mathrm{N}_{2}$ in the subtropical North Pacific Ocean. Nature 412, 635-638. doi: 10.1038/350 88063

Zhu, P., Li, Q., and Wang, G. (2008). Unique microbial signatures of the Alien Hawaiian marine sponge Suberites zeteki. Microb. Ecol. 55, 406-414. doi: 10.1007/s00248-007-9285-3

Conflict of Interest Statement: The authors declare that the research was conducted in the absence of any commercial or financial relationships that could be construed as a potential conflict of interest.
Received: 30 June 2014; accepted: 15 October 2014; published online: 04 November 2014.

Citation: Cuvelier ML, Blake E, Mulheron R, McCarthy PJ, Blackwelder P, Vega Thurber RL and Lopez JV (2014) Two distinct microbial communities revealed in the sponge Cinachyrella. Front. Microbiol. 5:581. doi: 10.3389/fmicb.2014.00581

This article was submitted to Aquatic Microbiology, a section of the journal Frontiers in Microbiology.

Copyright (c) 2014 Cuvelier, Blake, Mulheron, McCarthy, Blackwelder, Vega Thurber and Lopez. This is an open-access article distributed under the terms of the Creative Commons Attribution License (CC BY). The use, distribution or reproduction in other forums is permitted, provided the original author(s) or licensor are credited and that the original publication in this journal is cited, in accordance with accepted academic practice. No use, distribution or reproduction is permitted which does not comply with these terms. 